\title{
Involvement of common intermediate 3-hydroxy-L-kynurenine in chromophore biosynthesis of quinomycin family antibiotics
}

\author{
Yuki Hirose $^{1}$, Kenji Watanabe ${ }^{2}$, Atsushi Minami ${ }^{1}$, Takemichi Nakamura ${ }^{3}$, Hiroki Oguri ${ }^{1}$ and Hideaki Oikawa ${ }^{1}$ \\ Quinomycin antibiotics, represented by echinomycin, are an important class of antitumor antibiotics. We have recently \\ succeeded in identification of biosynthetic gene clusters of echinomycin and SW-163D, and have achieved heterologous \\ production of echinomycin in Escherichia coli. In addition, we have engineered echinomycin non-ribosomal peptide synthetase \\ to generate echinomycin derivatives. However, the biosynthetic pathways of intercalative chromophores quinoxaline-2-carboxylic \\ acid (QXC) and 3-hydroxyquinaldic acid (HQA), which are important for biological activity, were not fully elucidated. Here, we \\ report experiments involving incorporation of a putative advanced precursor, $(2 S, 3 R)-\left[6^{\prime}-{ }^{2} \mathrm{H}\right]-3$-hydroxy-L-kynurenine, and \\ functional analysis of the enzymes Swb1 and Swb2 responsible for late-stage biosynthesis of HQA. On the basis of \\ these experimental results, we propose biosynthetic pathways for both QXC and HQA through the common intermediate \\ 3-hydroxy-L-kynurenine.
}

The Journal of Antibiotics (2011) 64, 117-122; doi:10.1038/ja.2010.142; published online 24 November 2010

Keywords: biosynthesis; echinomycin; Streptomyces lasaliensis; Streptomyces sp; SW-163D

\section{INTRODUCTION}

Quinomycin class antibiotics, represented by echinomycin $(\mathbf{1})^{1}$ and SW-163D (2), ${ }^{2-4}$ are C2-symmetric cyclic depsipeptides with a pair of intercalative chromophores that show potent antibacterial, anticancer and antiviral activities (Figure 1). These antibiotics have potent DNA binding affinities at a level between $\mathrm{nm}$ and $\mathrm{mm}$ with different sequence selectivities. Reflecting these distinct affinities, quinomycin antibiotics show different inhibitory activities against various enzymes, such as DNA polymerase, RNA polymerase, reverse transcriptase and topoisomerase. ${ }^{5}$ Although thiocoraline has promising antitumor activity, most members of this family of compounds are toxic to mammalian cells. ${ }^{5}$ To improve the profiles between antitumor activity and toxicity, we studied the biosynthetic pathway of 1 and synthesizing its derivatives by genetic engineering. Recently, we have achieved de novo production of 1 using $E$. coli as a heterologous host. ${ }^{6,7}$ This facilitated synthesis of echinomycin derivatives by chemoenzymatic synthesis with $\mathrm{EcmTE}^{8}$ and by genetic engineering of non-ribosomal peptide synthetase. ${ }^{9,10}$

Quinomycin class peptide antibiotics have characteristic chromophores, which are essential components for their biological activities by bisintercalation into DNA. Among more than 20 congeners of this class of antibiotics, only two major chromophoresquinoxaline-2-carboxylic acid (QXC, 6) and 3-hydroxyquinaldic acid
(HQA, 8) - have been identified (Scheme 1). ${ }^{5}$ Although biosynthetic studies of these chromophores have been performed for $\mathbf{1}^{11,12}$ and triostin $^{13}$ and several gene clusters have been reported, ${ }^{6,9,14,15}$ little experimental data were obtained. Here, we report chromophore biosynthesis from L-tryptophan by unique pathway switching through the common intermediate $(2 S, 3 R)$-3-hydroxy-L-kynurenine (5).

\section{RESULTS}

Bioinformatics analysis of quinomycin family antibiotics In the biosynthetic study of echinomycin (1) and triostin, feeding experiments with isotope-labeled amino acids established that the QXC moiety was derived from L-tryptophan ${ }^{11}$ and that the N1 and N4 of QXC were derived from the indole and amino groups of L-tryptophan, respectively. ${ }^{13}$ Essential genes for echinomycin biosynthesis have been identified by de novo production of 1 using E. coli as a heterologous host. ${ }^{6}$ Exclusion of genes for backbone biosynthesis, modification, regulation and self-resistance leaves six genes suggested to be involved in the biosynthesis of QXC. Successful incorporation of $(2 S, 3 S)-\left[6^{\prime}-{ }^{2} \mathrm{H}\right]-3$-hydroxy-L-tryptophan (3a) supported the intermediacy of 3 , indicating that $\beta$-hydroxylation of tryptophan involves covalent attachment to L-tryptophan to the ACP domain of the non-ribosomal peptide synthetase (Ecm13), hydroxylation with cytochrome P-450 monooxygenase (Ecm12), and release of

${ }^{1}$ Division of Chemistry, Graduate School of Science, Hokkaido University, Sapporo, Japan; ${ }^{2}$ School of Pharmaceutical Sciences, University of Shizuoka, Shizuoka, Japan and ${ }^{3}$ Advanced Science Institute, RIKEN, Wako, Saitama, Japan

Correspondence: Professor H Oikawa, Division of Chemistry, Graduate School of Science, Hokkaido University, Kita-ku Kita 10 Nishi 8, Sapporo, Hokkaido 060-0810, Japan. E-mail: hoik@sci.hokudai.ac.jp 


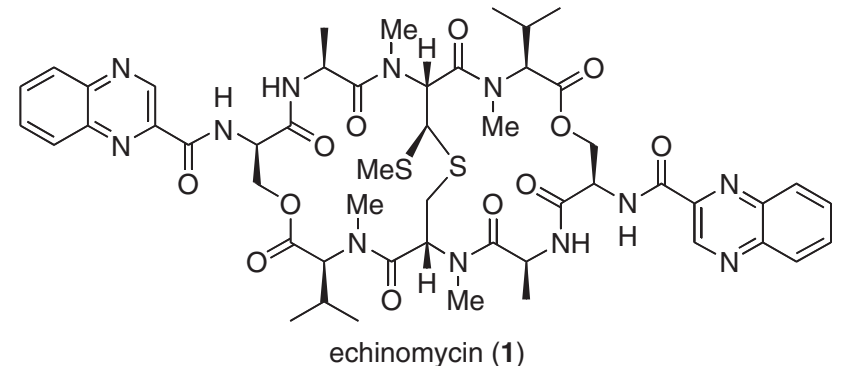

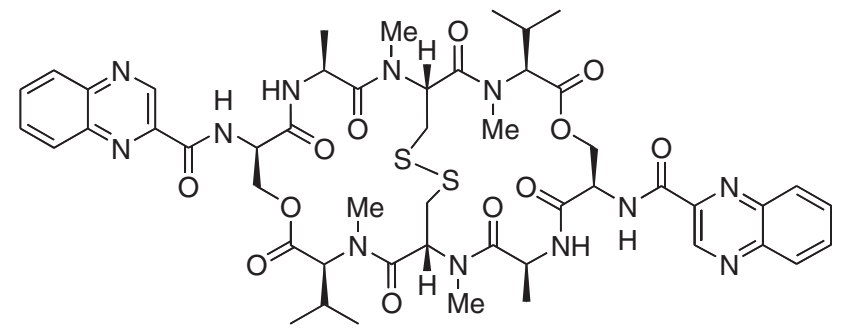

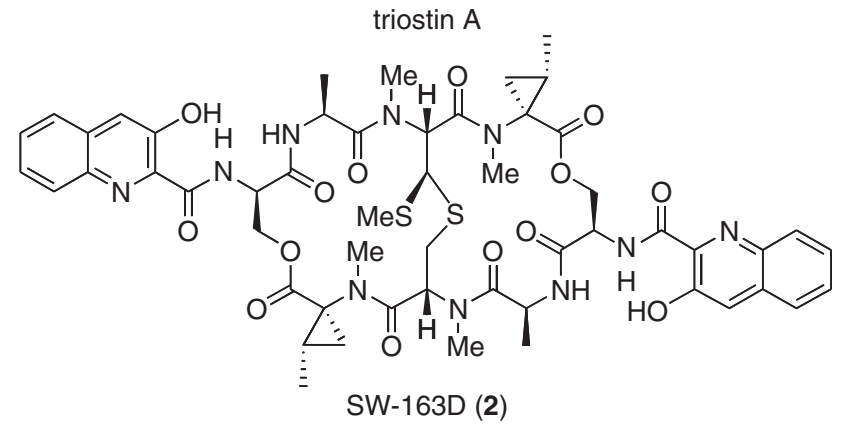

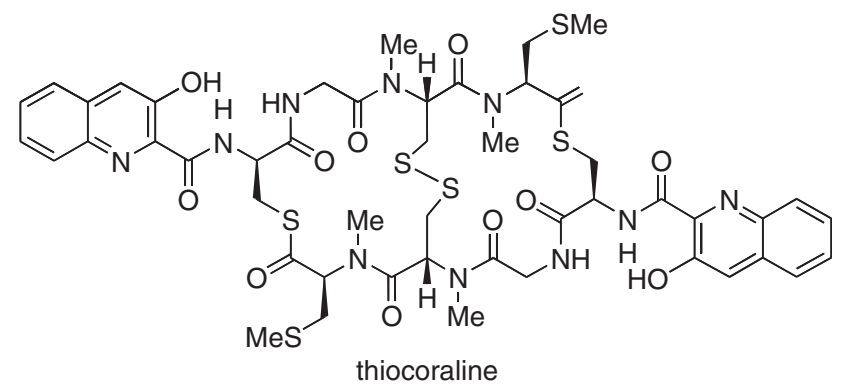

Figure 1 Quinomycin family antibiotics.

the hydroxylated product by the thioesterase $(\mathrm{Ecm} 2),{ }^{12}$ as in the case of tyrosine (novobiocin) ${ }^{16}$ and histidine (nikkomycin). ${ }^{17}$ Recently, four gene clusters of quinomycin-type antibiotics (Figure 1, 1, 2, triostin A and thiocoraline) have been identified, ${ }^{6,9,14,15}$ all of which share four homologous genes (identity \%) (ecm2/trsB/swb14/tioQ (65-75\%), ecm11/trsC/swb10/tioF (30-72\%), ecm12/trsB/swb13/tioI (64-80\%), and ecm 13/trsR/swb11/tioK (58-76\%)), which were proposed to be responsible for chromophore biosynthesis. Although the clusters of 1 and triostin A consist of homologous genes ecm $3 /$ trs $P$ $(80 \%)$ and $e c m 4 / t r s O(72 \%)$ probably responsible for QXC biosynthesis, ${ }^{6}$ the clusters of 2 and thiocoraline have alternative unique genes swb1/tioG (57\%) and swb2/tioH (58\%) probably involved in HQA biosynthesis, ${ }^{9}$ as shown in Scheme 1. Among the four common genes for echinomycin chromophore biosynthesis, the putative function (L-tryptophan 2,3-dioxygenase) of the remaining gene ecm11 suggested that 3-hydroxy-L-kynurenine (5) is a common intermediate in the chromophore biosynthesis.
Feeding experiments of $(2 S, 3 R)-\left(6^{\prime}-{ }^{2} \mathrm{H}\right)-3$-hydroxyL-kynurenine (5a)

To confirm the intermediacy of $\mathbf{5}$, feeding experiments with $(2 S, 3 R)$ $\left(6^{\prime}-{ }^{2} \mathrm{H}\right)$-3-hydroxy-L-kynurenine $(\mathbf{5 a})$ were used. The synthesis of 5a began with $\left(6^{\prime}-{ }^{2} \mathrm{H}\right)$-3-hydroxy-L-tryptophan (3a). ${ }^{12}$ Ozonolysis of $3 \mathbf{a}$ afforded formamide $4 \mathbf{a}$, which was hydrolyzed with trifluoroacetic acid to give $\mathbf{5 a}$ in $50 \%$ yield (two steps). The resulting labeled putative precursor $\mathbf{5} \mathbf{a}$ was administered to the echinomycin-producing strain Streptomyces lasaliensis. LC-MS analysis of echinomycin (1) thus obtained showed significant increases in 1 and 2 Da-shifted peak intensities at $m / z 1102\left(d_{1}-\mathrm{MH}^{+}\right)(41 \%)$ and $1103\left(d_{2}-\mathrm{MH}^{+}\right)(25 \%)$ compared with the natural abundance peak at $m / z 1101\left(\mathrm{MH}^{+}\right)$ (Figure 2a). The data indicated that $\mathbf{5 a}$ was incorporated into both QXC moieties of $\mathbf{1}$ in a highly efficient manner. Similarly, feeding of $\mathbf{5 a}$ to Streptomyces sp. SNA15896 gave monodeuterated and dideuterated SW-163D, as evidenced by the observation of the peaks at $m / z$ $1128\left(d_{1}-\mathrm{MH}^{+}\right)(22 \%)$ and $1129\left(d_{2}-\mathrm{MH}^{+}\right)(2 \%)$ were increased (Figure 2b). In this case, only one of the HQA moieties was incorporated into 2, probably due to significant dilution of the labeled precursor before the dimerization step of the monomeric tetrapeptide precursor. These results from feeding experiments supported the suggestion that $\mathbf{5}$ is a common intermediate in the biosyntheses of both QXC and HQA.

\section{Cloning, expression, and purification of Swb1 and Swb2}

On the basis of the results of the bioinformatics analyses described above, we speculated that two gene products, Swb1 (aminotransferase) and Swb2 (oxidoreductase), were involved in the transformation of 3-hydroxy-L-kynurenine (5) to HQA. Thus, the last two steps are (1) transamination of $\mathbf{5}$ and concomitant imine formation giving 3-hydroxykynurenic acid (7); (2) the subsequent reduction and concomitant dehydration giving HQA (8), as shown in Scheme 1. To obtain direct support of this proposal, enzymatic conversion of 5-8 was examined.

Both swb1 and swb2 genes were amplified by PCR from genomic DNA. Amplicons were purified, digested with NdeI/XhoI, and then inserted into the pET28b vector with incorporation of an $N$-terminal $\mathrm{His}_{6}$ tag. The resulting plasmids, pYHSwb1 and pYHSwb2, were used to transform E. coli BL21 (DE3) and Rosetta strains, respectively. The recombinant Swb1 and Swb2 were successfully expressed in E. coli strains at $15^{\circ} \mathrm{C}$ as soluble proteins and purified by Ni-chelating affinity chromatography. SDS-polyacrylamide gel electrophoresis analysis indicated that the purities of the recombinant proteins are $>90$ and $>70 \%$, respectively (Figure 3 ).

\section{Enzymatic activity of Swb1 and Swb2, and identification of the} enzymatic reaction products

Enzyme assay of the putative aminotransferase Swb1 with 5a was conducted in the presence of pyridoxal- $5^{\prime}$-phosphate (pPLP) and $\alpha$-ketoglutarate. In LC-MS analysis of the reaction products, a novel peak was observed on selective ion monitoring at $\mathrm{m} / \mathrm{z}$ 207. Comparison of the enzymatic product with a synthetic standard 7 in LC-MS analysis, we concluded that the product was identical to 7 (Figure 4a). The second enzymatic reaction of the putative oxidoreductase Swb2 was carried out on 7 in the presence of NADPH. Again in LC-MS analysis, a new peak appeared at $12.7 \mathrm{~min}$ on monitoring $\mathrm{m} / \mathrm{z} 190$. This peak was identical to synthetic 8 (Figure $4 \mathrm{~b}$ ). Although Swb1 also converted from kynurenine (9) to kynurenic acid (10) (Figure 4c), Swb2 did not give any new peaks using $\mathbf{1 0}$ as a substrate. These results indicated that $\mathbf{5}$ is an intermediate in the biosynthesis of $\mathbf{8}$. 


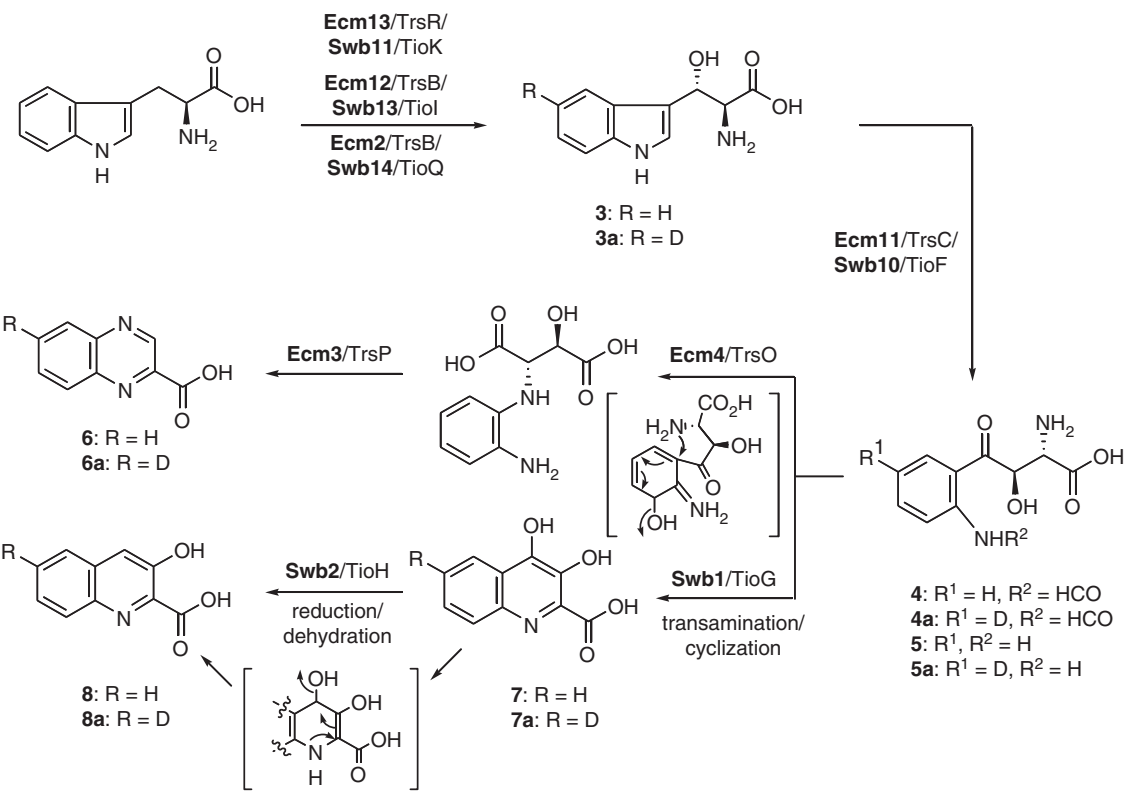

Scheme 1 Proposed biosynthetic pathway of chromophores of echinomycin (1) and SW-163D (2).

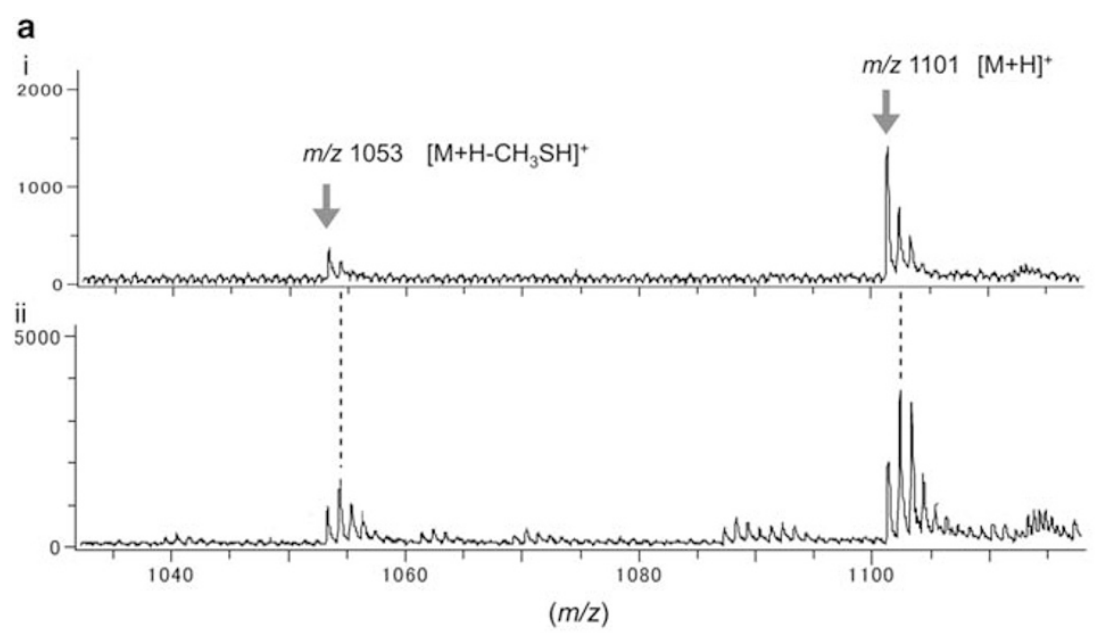

b

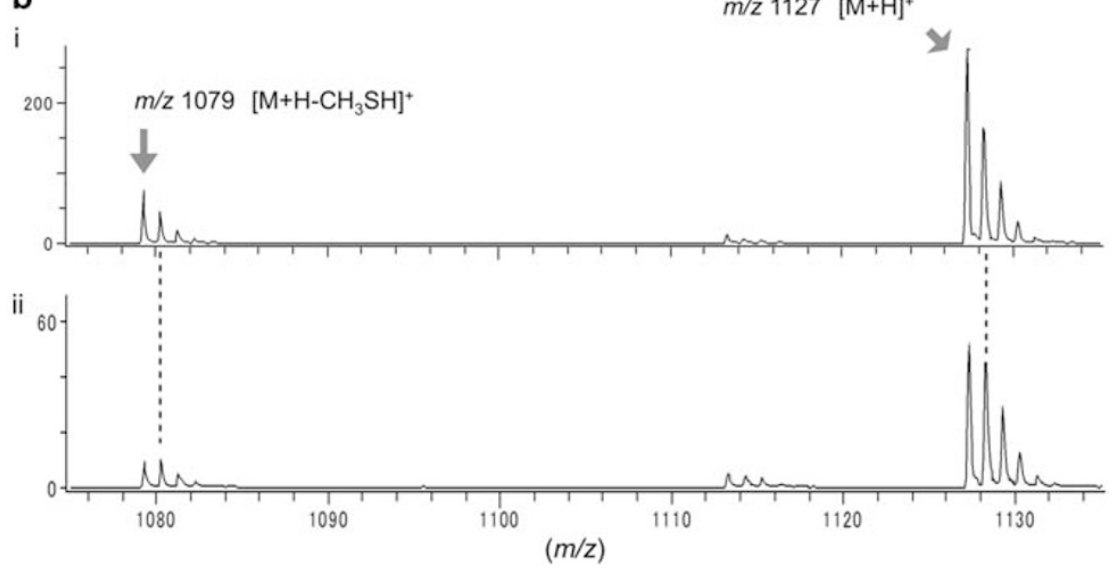

Figure 2 ESI-MS spectra of echinomycin (1) and SW-163D (2) from feeding experiments with (2S, 3R)-(6'-2 $\left.{ }^{2}\right)-3-$ hydroxy-L-kynurenine (5a). (a) (i) nonlabeled 1; (ii) 1 obtained from feeding experiment. (b) (i) non-labeled 2; (ii) 2 obtained from feeding experiment. Assays and HPLC conditions are available in Experimental section. 


\section{DISCUSSION}

We performed a feeding experiment with $\left(6^{\prime}-{ }^{2} \mathrm{H}\right)$-3-hydroxy-L-kynurenine (5a) to strains producing echinomycin and SW-163D. Efficient incorporation of $\mathbf{5 a}$ confirmed its intermediacy in the biosynthesis of both chromophores, QXC 6 and HQA 8. Intermediacy of 3 and a

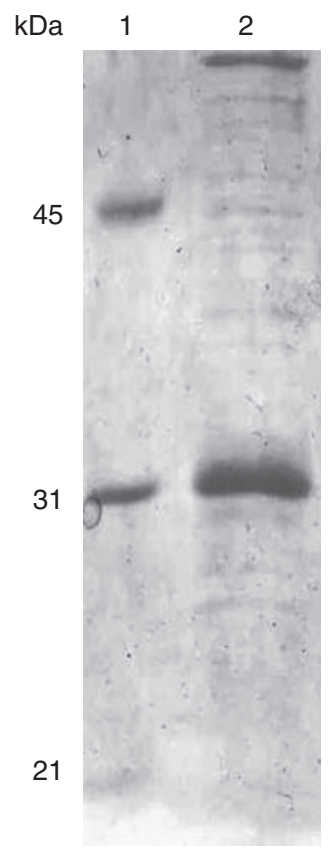

b

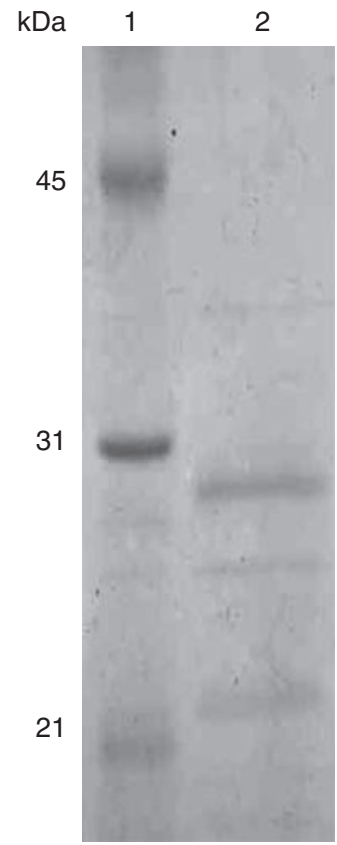

Figure 3 SDS-polyacrylamide gel electrophoresis analysis showing partially purified Swb1 (a) and Swb2 (b): lane 1, size markers; lane 2, partially purified Swb1 or Swb2.
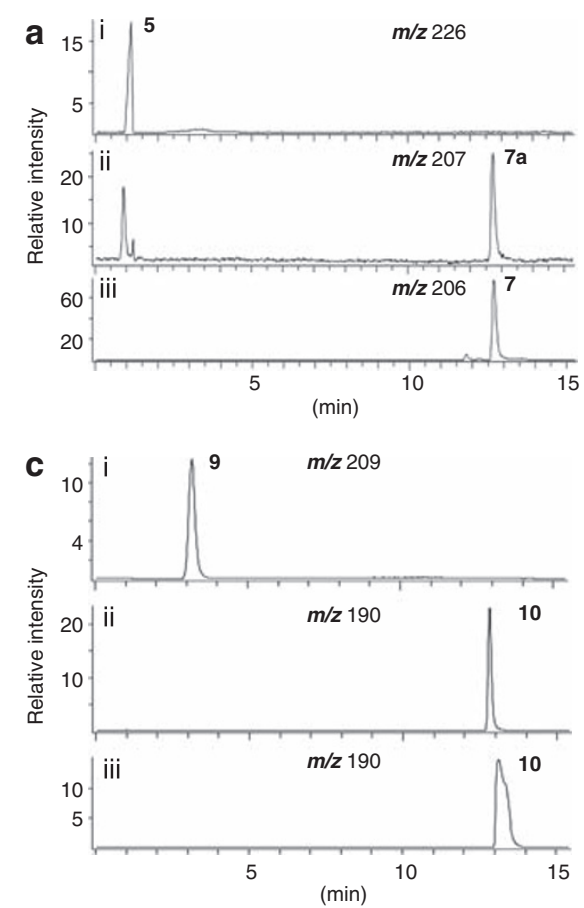

5 was further supported by the results of bioinformatics studies indicating that common gene homologs (ecm2/trsB/swb14/tioQ, ecm11/trsC/swb10/tioF, ecm12/trsB/swb13/tioI and ecm13/trsR/swb11/ tioK) for $\beta$-hydroxylation of L-tryptophan and oxidative cleavage of indole were found in the gene clusters of four quinomycin family members. In vitro functional analysis of enzymes Swb1 and Swb2 established conversion of $\mathbf{5}$ to HQA $\mathbf{8}$.

In a previous study of the biosynthesis of thiocoraline, Salas and colleagues ${ }^{15}$ proposed that kynurenine $(9)$ derived from L-tryptophan with TioF (L-tryptophan-2,3-dioxygenase) and TioL (arylformamidase) is an intermediate that is further transformed with $\mathrm{TioH}$ (oxidoreductase) and TioI (cytochrome P-450 monooxygenase) to HQA 8. Tsodikova and colleagues ${ }^{18}$ reported functional analysis of TioF, which converted tryptophan to $\mathbf{9}$, supporting the intermediacy of 9. On the other hand, we unambiguously established enzymatic conversion of $\mathbf{5}$ to HQA 8 with Swbl (Tiog homolog) and Swb2 (TioH homolog). In addition, our data in the feeding experiment and bioinformatics analysis strongly suggest that cytochrome P-450 monooxygenase homologs Ecm12/TrsB/Swb13/TioI are involved in hydroxylation of L-tryptophan, but not that of quinaldic acid. These data did not fit Salas' proposed pathway. We speculated that both 2,3-dioxygenase homologs Swb10 and TioF can catalyze oxidative cleavage of not only tryptophan, but also 3 , indicating functional analysis of TioF is not conclusive evidence on the intermediacy of $\mathbf{9}$.

Analysis of chromophore biosynthesis can yield insight into one of the strategies by which microorganisms create novel pathways for secondary metabolites. Natural peptides often incorporate hydroxylated amino acids. ${ }^{16,17,19,20}$ In chromophore biosynthesis, the producing strains utilize similar $\beta$-hydroxylation system consisting of cytochrome P-450, non-ribosomal peptide synthetase, and discrete thioesterase for conversion of L-tryptophan to $3 .{ }^{16,17}$ Chromophore biosynthetic clusters for 1 and $\mathbf{2}$ consist of genes encoding enzymes for tryptophan metabolism, such as kynurenic acid ${ }^{21}$ and nicotinic

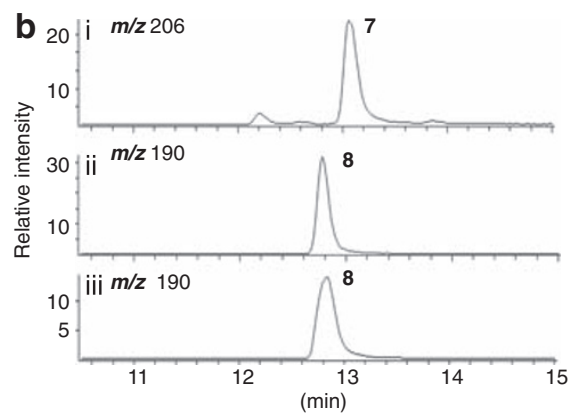

Figure 4 LC-MS analysis of enzymatic reaction products with Swb1 and Swb2 (ESI-positive mode). (a) (i) the substrate 5; (ii) reaction products with Swb1; (iii) authentic sample of the product 7. (b) (i) the substrate 7; (ii) reaction products with Swb2; (iii) authentic sample of the product 8. (c) (i) the substrate 9; (ii) reaction products with Swb1; (iii) authentic sample of the product 10. Assays and HPLC conditions are available in Experimental section. 
a

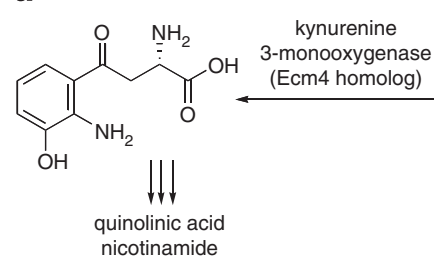

Tryptophan metabolism

b

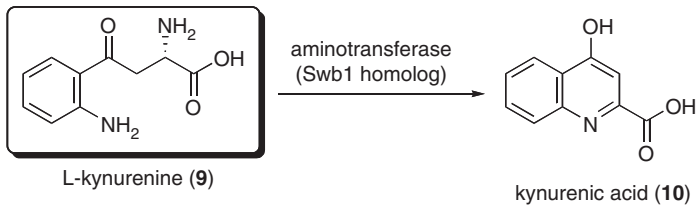

Chromophore biosynthesis

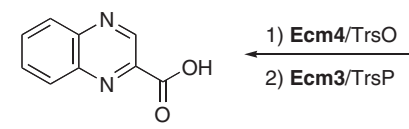

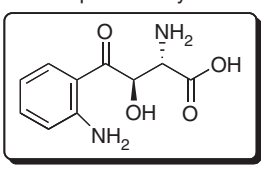

1) $\mathrm{Swb1/TioG}$

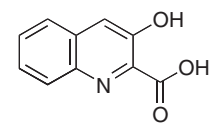

Scheme 2 Gene homologs found in primary and secondary metabolites.

acid, ${ }^{22,23}$ which are presumably different from the constitutive enzymes (Scheme 2). After conversion of 3-5 with tryptophan-2, 3-dioxygenase homolog, this common intermediate is transformed into either 7 with aminotransferase homolog or rearranged product with monooxygenase homolog (Scheme 1). Final transformations to chromophores $\mathbf{6}$ and $\mathbf{8}$ are catalyzed by specific redox enzymes such as Ecm3 and Swb2. Therefore, the strategy for creating novel pathways can be achieved by: (1) incorporation of modification enzymes transforming a common precursor to an unusual precursor; (2) duplication of existing genes and mutation to change function and; (3) recruiting additional enzyme to optimize target structure.

Although arylformamidase is an essential enzyme for kynurenine biosynthesis, the corresponding gene is not found in any of the four quinomycin family gene clusters. Initially, tiol and ecm14 (trsF) were proposed to catalyze this reaction, ${ }^{6,15}$ but low-sequence homology and absence of the $\mathrm{N}$-formamidase gene in the SW-163 gene cluster suggested lack of this gene in all quinomycin gene clusters. In echinomycin biosynthesis, the gene for the aryl-carrier protein for loading of QXC chromophore is not present on the gene cluster, but FabC involved in the fatty-acid biosynthesis is acted as an alternative acyl-carrier protein. ${ }^{24}$ Therefore, arylformamidase in the biosynthesis of nicotinic acid pathway may be used as an alternative.

We have already established the de novo synthesis of echinomycin by introducing three plasmids carrying non-ribosomal peptide synthetase genes, QXC biosynthetic genes and other auxiliary genes into E. coli. The findings presented in this paper will lead to switching of the chromophore from QXC to HQA by exchanging two genes, that is, ecm3-ecm4 to $s w b 1$-swb2. This will add options for diversification of quinomycin skeleton with engineering of biosynthetic pathways. ${ }^{25,26}$

\section{EXPERIMENTAL PROCEDURE}

\section{Chemicals}

$(2 S, 3 S)-\left(6^{\prime}-{ }^{2} \mathrm{H}\right)-3$-hydroxy-L-tryptophan, ${ }^{12} \mathrm{HQA}^{27}$ and $(2 S, 3 R)$-3-hydroxy-Lkynurenic acid ${ }^{28}$ were synthesized as reported previously. All reagents commercially supplied were used as received. Optical rotations were recorded on JASCO DIP-360 digital polarimeter. NMR spectra were obtained on JEOL ECP300 and JEOL $\alpha-400$ spectrometers for solution of $\mathrm{CD}_{3} \mathrm{OD} .{ }^{1} \mathrm{H}$ and ${ }^{13} \mathrm{C}$ chemical shifts were referenced to the solvent signals: 3.30 and 49.0 p.p.m. for $\mathrm{CD}_{3} \mathrm{OD}$. Mass spectra were recorded on JEOL JMS-T100CS (ESI). Flash column chromatography was performed using Kanto Silica Gel 60N.

\section{Bacterial strains, media and culture conditions}

Streptomyces lasaliensis ATCC 35851 and Streptomyces sp. SNA15896 were grown at $30^{\circ} \mathrm{C}$ on R2YE medium containing $0.4 \%$ maltose, $1.0 \%$ malt extract
(Difco) and $0.4 \%$ yeast extract (Difco). All E. coli strains BL21 (DE3) (Invitrogen, Tokyo, Japan) and Rosetta (Novagen, Tokyo, Japan) in this study were grown following standard protocols.

\section{$(2 S, 3 R)-\left(6^{\prime}-{ }^{2} \mathrm{H}\right)-\mathrm{N}$-formyl-3-hydroxy-L-kynurenine (4a)}

A stirred solution of $(2 S, 3 S)-\left(6^{\prime}{ }^{2} \mathrm{H}\right)-3$-hydroxy-L-tryptophan $(3 \mathrm{a}, 100 \mathrm{mg}$, $0.45 \mathrm{mmol})$ in $\mathrm{MeOH}(30 \mathrm{ml})$ was treated with ozone at $-78^{\circ} \mathrm{C}$ for $25 \mathrm{~min}$. Excess dimethylsulfide $(1 \mathrm{ml}, 13.6 \mathrm{mmol})$ was added, and stirring was continued to room temperature. The volatile was removed in vacuo and the resultant residue was purified by HPLC $\left(20 \% \mathrm{CH}_{3} \mathrm{CN} / 0.1 \% \mathrm{HCOOH}\right.$ in $\mathrm{H}_{2} \mathrm{O}$, 0-10 min, 30\%; 10-30 min, linear gradient 30-50\%; 30-35 min, 50\%; UV at $200 \mathrm{~nm}, 2 \mathrm{ml} \mathrm{min}^{-1}, 30^{\circ} \mathrm{C}$ ) with a column (Inertsil ODS-3, $\phi 3.0250 \mathrm{~mm}$, GL Science) to give $4 \mathrm{a}(56.4 \mathrm{mg}, 53 \%)$ along with an identified by-product $(28 \mathrm{mg})$. 4a: a colorless oil. ${ }^{1} \mathrm{H}-\mathrm{NMR}\left(300 \mathrm{MHz}, \mathrm{CD}_{3} \mathrm{OD}\right) \delta 8.47(1 \mathrm{H}, \mathrm{d}$, $J=8.3 \mathrm{~Hz}), 8.38(1 \mathrm{H}, \mathrm{s}), 7.84(1 \mathrm{H}, \mathrm{s}), 7.57(1 \mathrm{H}, \mathrm{d}, J=8.3 \mathrm{~Hz}), 5.38(1 \mathrm{H}, \mathrm{d}$, $J=3.4 \mathrm{~Hz}), 3.99(1 \mathrm{H}, \mathrm{d}, J=3.4 \mathrm{~Hz}) ;{ }^{13} \mathrm{C} \mathrm{NMR}\left(75 \mathrm{MHz}, \mathrm{CD}_{3} \mathrm{OD}\right) \delta 201.6,170.3$, $162.3,139.0,134.7,132.0,130.2,125.7,123.5,73.2,58.6$; HRMS (ESI) calcd. for $\mathrm{C}_{11} \mathrm{H}_{12} \mathrm{DN}_{2} \mathrm{O}_{5}[\mathrm{M}+\mathrm{H}]^{+}$254.0886; found 254.0839; $[\alpha]_{\mathrm{D}}^{27}-14.0$ (c 0.5 , $\mathrm{MeOH})$.

\section{(2S 3R)- $\left(6^{\prime}-{ }^{2} \mathrm{H}\right)-3$-hydroxy-L-kynurenine (5a)}

To a stirred solution of amide $4 \mathbf{a}(56 \mathrm{mg}, 0.23 \mathrm{mmol})$ in $\mathrm{H}_{2} \mathrm{O}(10 \mathrm{ml})$ was added trifluoroacetic acid $(0.5 \mathrm{ml}, 6.6 \mathrm{mmol})$ at room temperature. The mixture was stirred for $1 \mathrm{~h}$ and then lyophilized to give a residue, which was purified by HPLC under the same conditions as $4 \mathbf{a}$ to afford $5 \mathbf{a}(50.5 \mathrm{mg}, 95 \%)$. 5a: an amorphous solid; ${ }^{1} \mathrm{H}-\mathrm{NMR}\left(300 \mathrm{MHz}, \mathrm{CD}_{3} \mathrm{OD}\right) \delta 7.58(1 \mathrm{H}, \mathrm{s}), 7.25$ $(1 \mathrm{H}, \mathrm{d}, J=8.4 \mathrm{~Hz}), 6.73(1 \mathrm{H}, \mathrm{d}, J=8.4 \mathrm{~Hz}), 5.43(1 \mathrm{H}, \mathrm{d}, J=3.1 \mathrm{~Hz}), 4.06(1 \mathrm{H}, \mathrm{d}$, $J=3.1 \mathrm{~Hz}) ;{ }^{13} \mathrm{C}-\mathrm{NMR}\left(75 \mathrm{MHz}, \mathrm{CDCl}_{3}\right) \delta 198.3,170.6,135.7,130.3,124.4$, 122.3, 119.3, 118.3, 70.5, 57.6; HRMS (ESI) calcd. for $\mathrm{C}_{10} \mathrm{H}_{12} \mathrm{DN}_{2} \mathrm{O}_{4}[\mathrm{M}+\mathrm{H}]^{+}$ 226.0937; found 226.0902; $[\alpha]_{\mathrm{D}}^{27}+18.5\left(c 0.08, \mathrm{H}_{2} \mathrm{O}\right)$.

\section{Feeding Experiments with $(2 S, 3 R)-\left(6^{\prime}-{ }^{2} \mathrm{H}\right)-3$-hydroxy-} L-kynurenine (5a)

Sterile R2YE medium $(100 \mathrm{ml})$ was inoculated with spore suspension $\left(\mathrm{H}_{2} \mathrm{O}\right.$, $5 \mathrm{ml}$ ) of Streptomyces sp. SNA15896 from a 7-day R2YE plate. The culture was incubated at $30^{\circ} \mathrm{C}$ and 130 r.p.m. On the third day after inoculation, the aqueous solution $(5 \mathrm{ml})$ of $20 \mathrm{mg}$ of isotopically labeled $\mathbf{5 a}$ filtered through sterilized microfilter $(0.22 \mu \mathrm{m})$ was added into the culture and incubation was continued for further 4 days. The cells were harvested by centrifugation at $5000 \mathrm{~g}$. The resultant supernatants was extracted with EtOAc. Acetone extracts of the mycelia were concentrated and extracted with EtOAc. Both extracts from the supernatants and the mycelia were combined and concentrated in vacuo to yield the residue, which was dissolved into $\mathrm{MeOH}(2 \mathrm{ml})$. The extract filtered with microfilter $(0.22 \mu \mathrm{m})$ was directly analyzed by LC-ESI-MS (ESI-positive mode) (ZORBAX XDB-C18, Agilent, $\phi 2.150 \mathrm{~mm}$ ); $0.2 \mathrm{ml} \mathrm{min}^{-1}, 30^{\circ} \mathrm{C}$, solvent system, $\mathrm{CH}_{3} \mathrm{CN} / 0.1 \%$ TFA in $\mathrm{H}_{2} \mathrm{O}, 0-5 \mathrm{~min}, 20 \%$; 5-25 min, linear gradient $20-100 \%$; $25-30 \mathrm{~min}, 100 \%$. 
Similar feeding experiment was used to $S$. lasaliensis in the essentially same manner. Labeled precursor was fed on the second day after inoculation and incubation was continued for further 4 days.

\section{Cloning, expression and purification of Swb1}

The $s w b 1$ gene was obtained by PCR amplification with SP-taq polymerase (LaboPass) using a genomic DNA from Streptomyces sp. SNA15896. Primers for swbl (swb1-Fw: 5'-AAAGAGAACCATATGGCAGCATCGGCGCCAG-3' and swb1-Rv: 5'-TTTGAGCTCGATGGCGACGCGCCGCTT-3') contained NdeI and $X h o I$ sites (underlined, restriction endonuclease site) and the amplified gene was cloned into the corresponding sites of pET28b vector (Novagen) to yield pYHSwb1 for the production of Swb1. E. coli. BL21 (DE3) transformed with pYHSwbl was incubated at $37^{\circ} \mathrm{C}$ overnight in $10 \mathrm{ml} \mathrm{LB}$ medium supplemented with kanamycin $\left(100 \mu \mathrm{g} \mathrm{ml}^{-1}\right)$. Each liter of fresh LB medium with the same antibiotics at the same concentration as described above was inoculated with $5 \mathrm{ml}$ of the overnight culture and incubated at $37^{\circ} \mathrm{C}$ until the optical density at $600 \mathrm{~nm}$ reached 0.6. Then, expression of $s w b 1$ gene was induced with $100 \mu \mathrm{M}$ isopropyl- $\beta$-D-thiogalactopyranoside (IPTG) at $15^{\circ} \mathrm{C}$. Incubation was continued for another $24 \mathrm{~h}$, after which cells were harvested by centrifugation at $2500 \mathrm{~g}$. All subsequent procedures were performed at $4{ }^{\circ} \mathrm{C}$ or on ice. Harvested cells were resuspended in disruption buffer $(0.1 \mathrm{~m}$ Tris- $\mathrm{HCl}$ ( $\mathrm{pH} 7.2)$ and $20 \%(\mathrm{v} / \mathrm{v})$ glycerol). After addition of PLP (a final concentration $10 \mu \mathrm{M})$, cells were disrupted by a French Press cell, and the lysate was clarified by centrifugation at $18600 \mathrm{~g}$. The soluble fraction containing protein was applied to a Ni-NTA affinity column (GE Healthcare, Tokyo, Japan) previously equilibrated with binding buffer ( $0.1 \mathrm{M}$ Tris- $\mathrm{HCl}$ ( $\mathrm{pH}$ 7.2), $10 \mu \mathrm{M}$ PLP and 20\% (v/v) glycerol) supplemented with $10 \mathrm{~mm}$ imidazole, at a flow rate of $1 \mathrm{ml} \mathrm{min}^{-1}$. The column was washed with the binding buffer with $10 \mathrm{~mm}$ imidazole, then proteins were eluted with a gradient of 10-500 mm imidazole over $100 \mathrm{ml}$ of the binding buffer. Fractions containing protein with target molecular weight were pooled. Buffer exchange into the reaction buffer ( $100 \mathrm{~mm}$ Tris-HCl, $20 \%$ (v/v) glycerol, $\mathrm{pH} 7.2$ ) was carried out using a PD-10 column (GE Healthcare). Protein concentration was estimated using the Bio-Rad protein assay kit (BioRad, Tokyo, Japan) with bovine immunoglobulin $\mathrm{G}$ as a standard. Purified protein samples were analyzed by SDS-polyacrylamide gel electrophoresis.

\section{Cloning, expression and purification of Swb2}

The $s w b 2$ gene was obtained by PCR amplification with primers (swb2-Fw: 5'-AAAAGTGCGCATATGAGTGTGTCCGGCAAG-3' and swb2-Rv: 5'-TTT GAGCTCGCAGCAAGACGGCGG- $3^{\prime}$ ) contained $\mathrm{NdeI}$ and XhoI sites (underlined, restriction endonuclease site) and the amplified gene was cloned into the corresponding sites of pET28b vector (Novagen) to yield pYHSwb2 for the production of Swb2. The procedure from transformation to purification of Swb2 was same as that of Swb1 except use of E. coli (DE3) Rosetta cell in transformation and absence of PLP in the buffers during purification.

\section{Enzymatic reactions with Swb1 and Swb2}

Swb1 assay was performed in a total volume of $100 \mu \mathrm{l}$ in Tris-HCl buffer ( $100 \mathrm{~mm}, \mathrm{pH} 7.2$ ) with $14 \mu \mathrm{M}$ Swb1, $10 \mu \mathrm{M}$ PLP and $100 \mu \mathrm{M} \alpha$-ketoglutarate at $30{ }^{\circ} \mathrm{C}$ for $12 \mathrm{~h}$. The substrate concentration was $100 \mu \mathrm{M}$ for 3-hydroxy-Lkynurenine (5) and L-kynurenine. Reactions were terminated by addition of $\mathrm{MeOH}(100 \mu \mathrm{l})$, and the resultant mixture was vortexed and centrifugated at $13000 \mathrm{~g}$ for $2 \mathrm{~min}$. After concentration of the supernatant using centrifugal evaporator, the residue was dissolved with water $(100 \mu \mathrm{l})$. The reaction products were analyzed by LC-ESI-MS (ESI-positive mode) (Wakosil II 5C18, Wako, Tokyo, Japan) $\phi 2.150 \mathrm{~mm}$ ); $0.2 \mathrm{ml} \mathrm{min}^{-1}, 30^{\circ} \mathrm{C}$, solvent system, $\mathrm{CH}_{3} \mathrm{CN} / 0.1 \%$ TFA in $\mathrm{H}_{2} \mathrm{O}, 0-5 \mathrm{~min}, 0 \%$; 5-15 min, linear gradient $0-100 \%$; $15-20 \mathrm{~min}, 100 \%$. Swb2 assays were performed in a total volume of $100 \mu \mathrm{l}$ in Tris- $\mathrm{HCl}$ buffer ( $100 \mathrm{~mm}, \mathrm{pH} 7.2)$ with $7 \mu \mathrm{m}$ Swb2 and $100 \mu \mathrm{m}$ NADPH at $30{ }^{\circ} \mathrm{C}$ for $12 \mathrm{~h}$. The substrate concentration was $100 \mu \mathrm{m}$ for 3-hydroxykynurenic acid (7) and kynurenic acid. Work-up and analytical conditions were performed in the same manner as in the experiment with Swbl.

\section{ACKNOWLEDGEMENTS}

We are indebted to Dr Tetsuo Tokiwano for preparation of 3-hydroxyquinaldic acid and to Dr N Washida, Daiichi-Sankyou Pharmaceutical Co. Ltd. for providing the SW-163 producing strain, Streptomyces sp. SNA15896. This work was supported by JSPS Grants-in-Aid for Scientific Research (B) 20310126 and by MEXT research grant on innovative area 22108002 to H Oikawa.

1 Dell, A. W. et al. Structure revision of the antibiotic echinomycin. J. Am. Chem. Soc. 97, 2497 (1975).

2 Kurosawa, K., Takahashi, K. \& Tsuda, E. SW-163C and E, novel antitumor depsipeptides produced by Streptomyces sp. I. Taxonomy, fermentation, isolation and biological activities. J. Antibiot. 54, 615-621 (2001).

3 Takahashi, K., Koshino, H., Esumi, Y., Tsuda, E. \& Kurosawa, K. SW-163C and E, novel antitumor depsipeptides produced by Streptomyces sp. II. Structure elucidation. J. Antibiot. 54, 622-627 (2001).

4 Nakaya, M. et al. Relative and absolute configuration of antitumor agent SW-163D. Biosci. Biotechnol. Biochem. 71, 2969-2976 (2007).

5 Dawson, S., Malkinson, J. P., Paumier, D. \& Searcey, M. Bisintercalator natural products with potential therapeutic applications: isolation, structure determination, synthetic and biological studies. Nat. Prod. Rep. 24, 109-126 (2007).

6 Watanabe, K. et al. Total biosynthesis of antitumor nonribosomal peptides in Escherichia coli. Nat. Chem. Biol. 2, 423-428 (2006).

7 Watanabe, K. \& Oikawa, H. Robust platform for de novo production of heterologous polyketides and nonribosomal peptides in Escherichia coli. Org. Biomol. Chem. 5, 593-602 (2007).

8 Koketsu, K., Oguri, H., Watanabe, K. \& Oikawa, H. Enzymatic macrolactonization in the presence of DNA leading to triostin A analogs. Chem. Biol. 15, 818-828 (2008).

9 Watanabe, K. et al. Rationally engineered total biosynthesis of a synthetic analogue of a natural quinomycin depsipeptide in Escherichia coli. Chem. Bio. Chem. 10, 1965-1968 (2009).

10 Watanabe, K. et al. Escherichia coli allows efficient modular incorporation of newly isolated quinomycin biosynthetic enzyme into echinomycin biosynthetic pathway for rational design and synthesis of potent antibiotic unnatural natural product. J. Am. Chem. Soc. 131, 9347-9353 (2009).

11 Yoshida, T., Katagiri, K. \& Yokozawa, S. Studies on quinoxaline antibiotics. II. Isolation and properties of quinomycins A, B, C. J. Antibiot. Ser. A 14, 330-334 (1961).

12 Koketsu, K., Oguri, H., Watanabe, K. \& Oikawa, H. Identification and stereochemical assignment of the $\beta$-hydroxytryptophan intermediate in the echinomycin biosynthetic pathway 8, 4719-4722 (2006).

13 Reid, D. G., Doddrell, D. M., Williams, D. H. \& Fox, K. R. A ${ }^{15} \mathrm{~N}$ nuclear magnetic resonance study of the biosynthesis of quinoxaline antibiotics. Biochim. Biophys. Acta 798, 111-114 (1984).

14 Praseuth, A. P. et al. Complete sequence of biosynthetic gene cluster responsible for producing triostin $A$ and evaluation of quinomycin-type antibiotics from Streptomyces triostinicus. Biotechnol. Prog. 24, 1226-1231 (2008).

15 Lombo, F. et al. Deciphering the biosynthesis pathway of the antitumor thiocoraline from a marine actinomycete and its expression in two streptomyces species. ChemBioChem 7, 366-376 (2006).

16 Chen, H. \& Walsh, C. T. Coumarin formation in novobiocin biosynthesis: beta-hydroxylation of the aminoacyl enzyme tyrosyl-S-NovH by a cytochrome P450 Novl. Chem. Biol. 8, 301-312 (2001).

17 Chen, H., Hubbard, B. K., O'Connor, S. E. \& Walsh, C. T. Formation of beta-hydroxy histidine in the biosynthesis of nikkomycin antibiotics. Chem. Biol. 9, 103-112 (2002).

18 Sheoran, A., King, A., Velasco, A., Pero, J. M. \& Garneau-Tsodikova, S. Characterization of TioF, a tryptophan 2,3-dioxygenase involved in 3-hydroxyquinaldic acid formation during thiocoraline biosynthesis. Mol. Biosyst. 4, 622-628 (2008).

19 Yin, X. H. \& Zabriskie, T. M. VioC is a non-heme iron, alpha-ketoglutarate-dependent oxygenase that catalyzes the formation of 3S-hydroxy-L-arginine during viomycin biosynthesis. Chem. Bio. Chem. 5, 1274-1277 (2004).

20 Strieker, M., Kopp, F., Mahlert, C., Essen, L. O. \& Marahiel, M. A. Mechanistic and structural basis of stereospecific $\mathrm{C}$ beta-hydroxylation in calcium-dependent antibiotic, a daptomycin-type lipopeptide. ACS Chem. Biol. 2, 187-196 (2007).

21 Han, Q., Fang, J. M. \& Li, J. Y. Kynurenine aminotransferase and glutamine transaminase $\mathrm{K}$ of Escherichia coli: identity with aspartate aminotransferase. Biochem. J. 360, 617-623 (2001).

22 Kurnasov, O. et al. NAD biosynthesis: identification of the tryptophan to quinolinate pathway in bacteria. Chem. Biol. 10, 1195-1204 (2003).

23 Lima, W. C., Varani, A. M. \& Menck, C. F. M. NAD biosynthesis evolution in bacteria: lateral gene transfer of kynurenine pathway in Xanthomonadales and Flavobacteriales. Mol. Biol. Evol. 26, 399-406 (2008).

24 Schmoock, G. et al. Functional cross-talk between fatty acid synthesis and nonribosomal peptide synthesis in quinoxaline antibiotic-producing streptomycetes. J. Biol. Chem. 280, 4339-4349 (2005).

25 Watanabe, K., Oguri, H. \& Oikawa, H. Enzymatic synthesis of molecular skeletons of complex antitumor antibiotics with non-ribosomal peptide synthetases. J. Synth. Org. Chem., Jpn. 67, 1152-1160 (2009).

26 Watanabe, K., Oguri, H. \& Oikawa, H. Diversification of echinomycin molecular structure by way of chemoenzymatic synthesis and heterologous expression of the engineered echinomycin biosynthetic pathway. Curr. Opin. Chem. Biol. 13, 189-196 (2009).

27 Riego, E., Bayo, N., Cuevas, C., Albericio, F. \& Alvarez, M. A new approach to 3-hydroxyquinoline-2-carboxylic acid. Tetrahedron 61, 1407-1411 (2005).

28 Behrman, E. J., Kiser, R. L., Garas, W. F., Behrman, E. C. \& Pitt, B. M. Conversion of 4-quinolones into 3-hydroxy-4-quinolones via the corresponding sulfates. J. Chem. Res. -S 164-165 (1995). 